\title{
Correction to: Large artery stiffness is associated with salt intake in young healthy black but not white adults: the African-PREDICT study
}

\author{
Michél Strauss $^{1} \cdot$ Wayne Smith $^{1,2} \cdot$ Ruan Kruger $^{1,2} \cdot$ Bianca van der Westhuizen $^{1} \cdot$ Aletta E. Schutte $^{1,2}$ (DD
}

Published online: 4 August 2018

(c) Springer-Verlag GmbH Germany, part of Springer Nature 2018

\section{Correction to: European Journal of Nutrition} https://doi.org/10.1007/s00394-018-1791-1

In the Original publication of the article Fig. 1 was published incorrectly. The correct figure is given below. The original article has been corrected.

The original article can be found online at https://doi.org/10.1007/ s00394-018-1791-1.

Aletta E. Schutte

Alta.Schutte@nwu.ac.za

1 Hypertension in Africa Research Team (HART), NorthWest University, Private Bag X6001, Potchefstroom 2520, South Africa

2 MRC Research Unit: Hypertension and Cardiovascular Disease, North-West University, Potchefstroom, South Africa

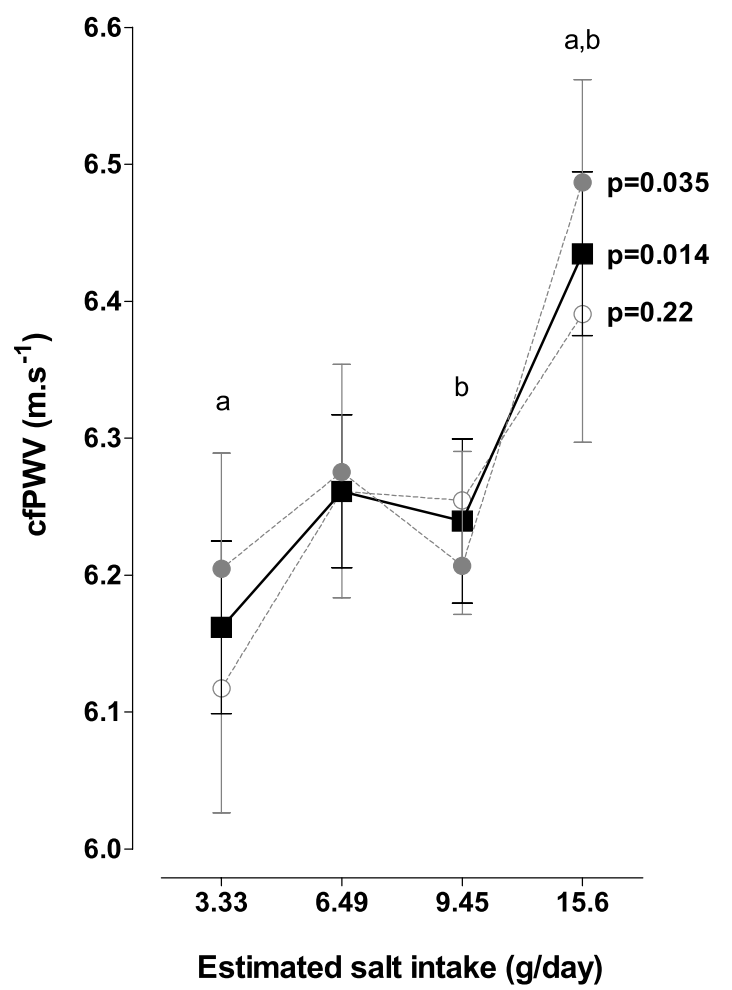

Estimated salt intake (g/day) 